\title{
Surface Modification of Cellulose with Silanes for Adhesive Application: Review
}

\author{
Ravindra V. Gadhave ${ }^{1 *}$, Pritam V. Dhawale ${ }^{1}$, Chaitali S. Sorate ${ }^{2}$ \\ ${ }^{1}$ Department of Polymer and Surface Engineering, Institute of Chemical Technology, Mumbai, India \\ ${ }^{2}$ Department of Microbiology, Savitribai Phule Pune University, Pune, India \\ Email: *ravi.gadhave3@gmail.com
}

How to cite this paper: Gadhave, R.V., Dhawale, P.V. and Sorate, C.S. (2021) Surface Modification of Cellulose with Silanes for Adhesive Application: Review. Open Journal of Polymer Chemistry, 11, 11-30. https://doi.org/10.4236/ojpchem.2021.1120 $\underline{02}$

Received: December 20, 2020

Accepted: May 27, 2021

Published: May 30, 2021

Copyright (c) 2021 by author(s) and Scientific Research Publishing Inc. This work is licensed under the Creative Commons Attribution International License (CC BY 4.0).

http://creativecommons.org/licenses/by/4.0/

\begin{abstract}
There has been an increasing interest in research on using bio-renewable polymers as a replacement to traditional synthetic polymers based on petroleum resources for adhesive applications. Cellulose, which is the most abundant biopolymer finds application as a reinforcing agent in conventional adhesives. However, natural polymer cellulose suffers from a few drawbacks like poor water resistance, low mechanical strength, and compatibility within the hydrophobic matrix. For emerging as sustainable alternatives for synthetic polymers, cellulose and its derivatives must have comparable physical, chemical, thermal, and mechanical properties to those of synthetic polymers. To achieve this, cellulose has been chemically modified as it has free hydroxyl groups which act as a site for modification. Among various techniques used crosslinking and silane modification have shown better properties. Various silanes have been identified and used for modifying both micro-cellulose and nano-cellulose, by the formation of covalent bonds. Silanes have the ability to react with the low number of free hydroxyl groups present in the cellulose surfaces, therefore promotes surface modification. Hence referring to the increase in the research works related to the silane modification of cellulose and its applicability focusing on wood adhesives, the main aim of this review paper is to summarize various works relating to this field.
\end{abstract}

\section{Keywords}

Cellulose, Biopolymer, Silane Modification, Adhesive, Renewable Material

\section{Introduction}

The realization of pollution in air [1] [2], water [3] [4], and soil [5] [6] due to the over-exploitation of using non-renewable and toxic petrochemicals, research is now shifting to the development and innovations in the areas of biopolymers [7] 
[8] [9] [10]. As the global energy crisis demands materials that are cost effective and comparable properties with petrochemicals, chemical modification of biopolymers has huge potential in the coming future. The researchers have identified usage of bio-based materials like starch [11], cellulose [12], lignin [13], tannin [14] [15], natural rubber latex [16], soy protein [17] [18] [19] and vegetable oils [20] [21] as an alternative resource for petroleum based materials. These materials have huge applications in the development of bio-based adhesives which have a lower negative impact on the environment. The increase in the amount of research works using these materials is due to the advantages of abundance in its availability, eco-friendliness, low cost, and very low emission of volatile organic solvents in adhesives [22] [23]. Although adhesive manufacturing industries use these bio-based materials at a relatively lower amount compared to petrochemicals and are at the introductory stage, the advantages like lower cost, readily available greener materials and chemical modification possibilities are much bigger.

With the ongoing research and development in bio-based adhesives and by continuous improvement in its properties, meeting the standards which can compete with commercial petrochemical-based adhesives, bio-based adhesives have huge scope in the point of commercialization [24] [25]. Cellulose being the most abundant biopolymer has been identified as a potential material for many applications [26]. The advantages the cellulose offer includes the possibility to undergo chemical modification and the easiness in preparation of composite materials using cellulose [27] [28].

Cellulose belongs to the high molecular weight polysaccharide family with glycosidic linkages. Cellulose consists of repeating units, cellobiose, which is a dimer of D-glucose with $\beta$-1,4 glycosidic linkage [26]. There are intramolecular hydrogen $(\mathrm{H})$ bonding and intermolecular hydrogen bonding in cellulose polymers. The terminal groups have a directional asymmetry whereas reducing ends contains a hemiacetal group. Figure 1 shows a detailed structure of cellulose.

Nanocellulose (NC) is a detached cellulosic material with one dimension in the nanometer range [29]. They may be nano fibrillated celluloses (CNF), cellulose nanocrystals (NCC or CNC), and bacterial nanocellulose. These are obtained by a top-down approach from biomasses by chemical or mechanical processes [30]. The general procedure for isolation of micro or nano cellulose is shown in Figure 2.

The cellulose can be used as reinforcement for thermoplastic and thermosetting polymers, as well as the template for functional composites [31]-[47]. Cellulose has the ability to adhere makes it an ideal biomaterial for developing green adhesives and coatings [48]-[53]. Nanocellulose in adhesives contributes to the enhancement in physical, mechanical, and thermal properties of wooden substrates and creates better adhesion. The hydroxyl group of cellulose makes the possibility for functionalization, and hence the binding property of nanocellulose has been enhanced [54]. 


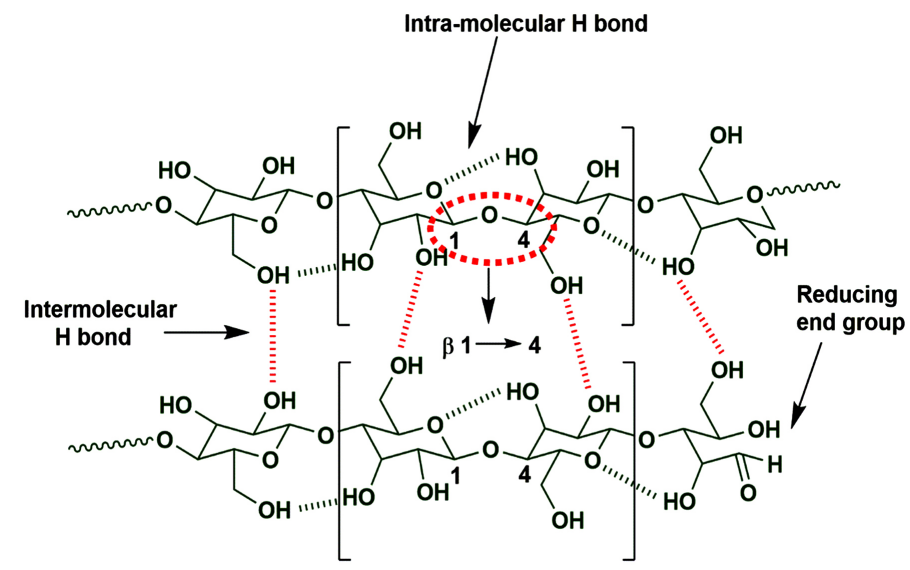

Figure 1. Structure of cellulose.

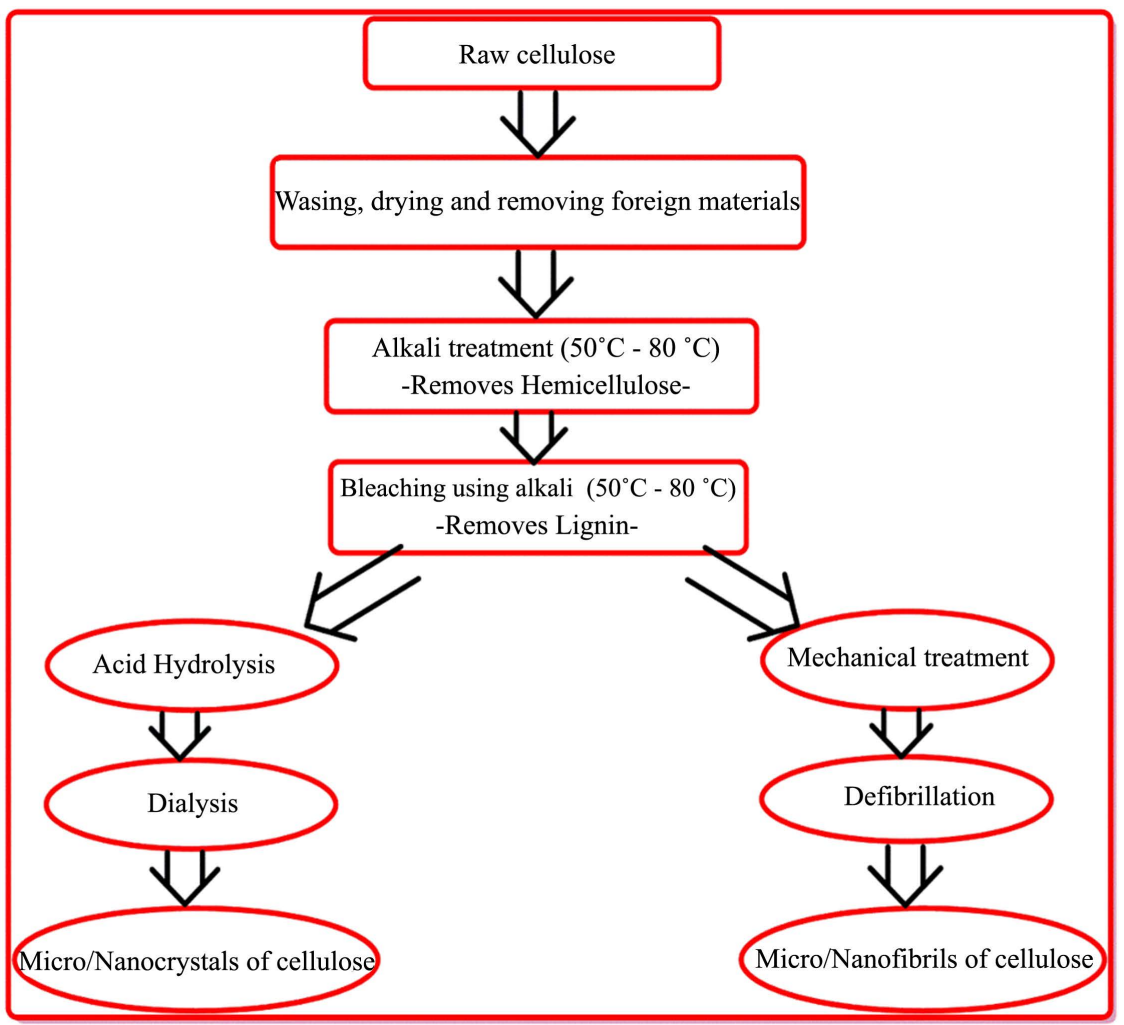

Figure 2. Procedure followed in the isolation of micro/nanocellulose.

Cellulose has been a part of adhesive as filler which reinforces the adhesive giving better properties. With the increasing amount of literature on chemical modifications of cellulose and its applications in adhesive sector, this review summarizes various works on silane modification in cellulose. As chemical modification of cellulose by silane coupling agents has shown improvement in physical, mechanical, and thermal properties with better interfacial morphology and compatibility of cellulose with matrices which contributed to better adhesion. Hence this review paper aims to showcase the importance of silane modification in cellulose and its application towards wood adhesives. 


\section{Cellulose Based Wood Adhesives}

For consolidation of wooden substrates, the adhesive must hold the substrates together. As the petrochemical based resins have shown their toxicity by formaldehyde release, bio-based adhesive found an alternative to this issue. Cellulose gets the attention due to its large abundancy and reinforcing behavior with polymer matrices. Various researchers have formulated wood adhesives with cellulose for enhancing mechanical and thermal properties of wood adhesive where the addition of cellulose has contributed to enhance the bonding strength. Jiang et al. conducted a study where the incorporation of dicarboxylic acid cellulose nanofibrils (CNF) into commercial adhesives such as polyvinyl acetate (PVAc) and starch adhesives showed enhancement in bonding strength [55]. Nanocomposite adhesive prepared by incorporating CNF to PVAc latex showed enhanced adhesive properties with reinforcing effects [56]. Another work where CNC incorporated PVAc wood adhesive showed enhancement in creep, hardness, and modulus of elasticity (MOE) of the adhesive films with better thermal stability [57]. 2\% CNF incorporated tannin-based adhesive for particleboards resulted in developing high performance particleboards with enhanced mechanical properties [58].

Urea-formaldehyde (UF) resin adhesive with reduced formaldehyde emission was produced upon adding 3-aminpropyltriethoxysilane (APS) and 3-methacryloxypropyltrimethoxysilane (MPS) modified CNC [59]. Cellulose nano-whiskers (CNW) were used to enhance the performance of soybean meal-based adhesive [60]. The results showed that using the CNW in the adhesive formulation improved the water resistance of plywood. In order to replace chemical adhesive, binding effect of CNF, prepared from the same novel nanofiber technology over wood flour (WF) board were investigated [61]. The three-dimensional binding effect of CNF was found for the board having a WF:CNF of 90:10, which was considered the optimal composition as it leads to improvement in the physical and mechanical properties. Composite boards of wood flour and a novel lingo-cellulose nanofiber (LCNF) were produced to investigate the binding effect(s) of LCNF [62]. The 85:15 ratio (of wood flour:LCNF) showed the close binding between LCNF and wood flour particles which resulted in the enhancement of physical and mechanical properties of the board. Three grades of liquid urea-formaldehyde (UF) resins with different formaldehyde emission levels such as super E0 (SE0), E0 and E1 were modified by adding different amounts of micro fibrillated cellulose (MFC, $5 \mathrm{wt} \%$ ) [63]. The incorporation of the MFC into the SE0 up to $30 \mathrm{wt} \%$ significantly decreased the formaldehyde emission from of the UF resin while this was not observed for E0 and E1 grade resins. The use of MFC in the UF resin can be an environmentally friendly solution for reducing the VOCs from the wood-based panel used for indoor furniture. A detailed investigation is being carried out, where particleboards are prepared out of small and larger particles from southern pine and sweetgum with varying content of MCC (microcrystalline cellulose) [64]. The study suggests that nature of species, 
its particle size, and MCC are the deciding factors for particleboard properties. Though addition of MCC results in higher mechanical properties, the problem of thickness swelling was the drawback. Whereas, replacing southern pine with sweetgum showed equal or better mechanical and physical properties. Thus, hardwood natured sweetgum performs favourably compared with southern pine. The effects of cellulose nanofibrils (CNFs) ratio, press program, particle size, and density on the vertical density profile (VDP) and internal bond (IB) strength of the wet-formed particleboard were investigated [65]. As the CNF ratio increased, there were noticeable increases in face density, while the core density slowly increased. A study by C.I.K. Diop et al. showed that lignocellulose nanofibrils (LCNF) act as a sustainable adhesive with good bonding ability for fiberboards [66]. An investigation on usage of cellulose nanofibrils (CNF) as a binder in the formulation of particleboard (PB) panels was conducted [67]. The panels were produced in four different groups of target densities with varying amounts of CNF binder. The panels were produced in four different groups of target densities with varying amounts of $\mathrm{CNF}$ binder. Cellulose nanofibers (CNF) incorporated cottonseed protein-based wood adhesives were found to be most effective at about a $2 \%$ additive level, giving $22 \%$ improvement in dry adhesive strength over the blank cottonseed protein as wood adhesive [68]. To increase bond strength, cellulose nanofibers were added to create nanocomposite adhesives and glutaraldehyde was also used to crosslink the proteins [69]. The bond strength of both zein and gluten adhesives was significantly increased by the addition of the cellulose nanofibers and/or glutaraldehyde. Aqueous solutions of dialdehyde cellulose (DAC) with various degrees of oxidation (DOs) and distinct concentrations were evaluated as robust adhesives for wood bonding [70]. DAC adhesives possessed a stronger bonding strength than the wood itself. UF adhesive mixtures with a $5 \%$ suspension of MFC at $0.5,1,3$, and $5 \mathrm{wt} \%$ loading levels based on the solid weight $(62.4 \%)$ of the UF adhesive were prepared [71]. The specimens bonded with UF adhesive containing the MFC showed better tensile shear strengths as compared to the control. LCNF showed improvement in the performance of polymeric diphenylmethane diisocyanate (pMDI) as a wood adhesive [72]. Output demonstrated the promise of developing high adhesion performance pMDI adhesive systems by using sustainable LCNF as reinforcement additives. The bonding strength, compatibility and thermal properties of the cellulose-based adhesive have improved significantly, confirming the positive effect of adding the silane coupling agent to the adhesive system. Silane coupling agent is commonly used to strengthen the interfacial interaction between cellulose hydroxyl groups. The alkoxysilanes have been demonstrated to be able to directly react with -Si-OH groups of silica thereby forming -Si-O-Si- bonds without any requirement of pre-hydrolysis [73]. First step is to activate the alkoxysilane by hydrolyzing the alkoxy groups off thereby forming the more reactive silanol groups [74]. As a result, the silanol may react with the hydroxyl groups of cellulose or condense themselves on the surfaces of cel- 
lulose and forming macromolecular network as shown in Figure 3 [75] [76].

Cellulose fibers are being considered as prospective reinforcing materials due to a number of advantages, including their abundance, low weight, biodegradability, low abrasive character, intriguing particular features, and the fact that they are waste biomass [77] [78] [79]. Whereas, moisture absorption, quality changes, limited heat stability, and poor compatibility with the hydrophobic polymer matrix are all downsides of cellulose fibers [80] [81]. In the current scenario, these disadvantages are the most significant obstacle limiting the productive and global development of cellulose as a bio-based alternative to develop modern adhesive. This paper reports new strategies for these issues by chemical modification.

\section{Interfacial Bonding between Cellulose Nanofibers and Polymer Matrix}

Crosslinking is a chemical modification, where a crosslinker connects two polymeric chains, consolidating and reducing the free spaces between the molecules. This causes enhancements in thermal, mechanical, and chemical properties of the polymer. Dialdehyde has been found as a class of crosslinker for PVA and cellulose blend. A recent study showed enhanced adhesion properties with improvements in thermal and mechanical properties on crosslinking PVA and MCC blends by glyoxal [7]. On the other hand, glutaraldehyde as a crosslinker for PVA hydrogels with different concentrations of CNC showed reinforcement [82]. In the study, glutaraldehyde was added to CNC-PVA suspension under the acidic condition for reaction initiation, and the blank sample where glutaraldehyde is added only with PVA without CNC, were also prepared. Figure 4 shows the crosslinking reaction of glutaraldehyde with nanocellulose (NC)-PVA. In the study, cross-linked CNC-PVA hydrogels showed a significant increase of 303\%

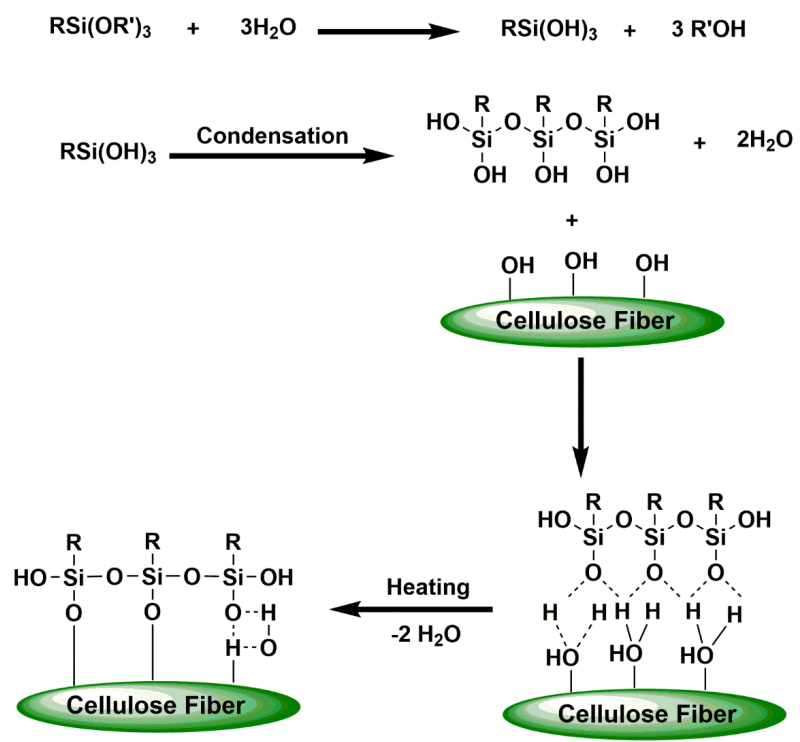

Figure 3. Hydrolysis and condensation reaction of silane with Cellulose. 


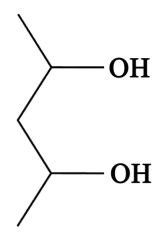

PVA

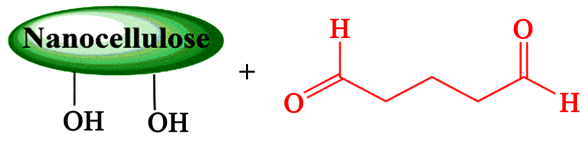

Glutaraldehyde

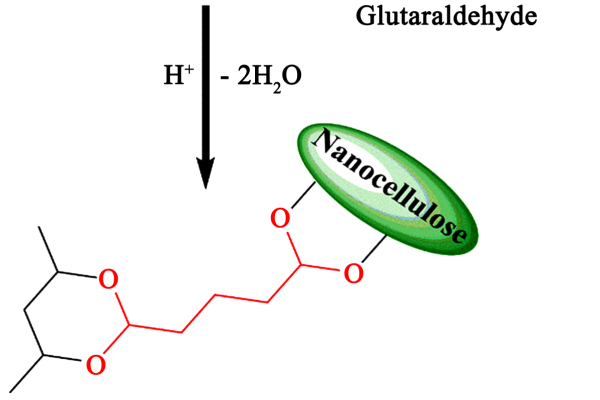

Glutaraldehyde crosslinked PVA-Nanocellulose

Figure 4. Crosslinking reaction of polyvinyl alcohol (PVA) and nanocellulose by glutaraldehyde.

in compressive strength with $1 \mathrm{wt} \%$ addition of CNCs at $60 \%$ strain. Moreover, a decrease in the swelling ratio with an increase in $\mathrm{CNC}$ content on crosslinked hydrogels was observed.

Thermal and mechanical properties showed enhancements upon introducing CNC in PVA matrix and by crosslinking the composite by borax (sodium tetraborate decahydrate) [83]. The hydroxyl groups of PVA and CNC are targeted by the crosslinker, borate ions from borax act on the hydroxyl groups and forms complexes, the crosslinking reaction is shown in Figure 5. The work reported that with the addition of CNCs, the crosslinked composite at high temperature was able to bear higher loads.

Crosslinked PVA-CNC films showed an increase in decomposition temperature, glass transition temperature ( $\mathrm{Tg}$ ), and mechanical properties, while the degree of crystallization, moisture uptake, and melting temperature decreased in comparison to blank PVA samples. Upon adding CNC in the crosslinked PVA nanocomposites, an increase in crystallization temperature has been reported. A study where CNCs having carboxyl and aldehyde functionalities were reinforced in different concentration with acetal-bonding cross-linked polyvinyl alcohol (PVA) films and its effects on mechanical, thermal, and barrier properties of the film were investigated [84]. Mechanically treated partially carboxylated dialdehyde cellulose results in carboxyl and aldehyde functional CNCs, and for the comparative study, a reference sample where $\mathrm{CNC}$ without reactive aldehydes was also prepared. An investigation was carried out, in which CNF or nano fibrillated cellulose-based hydrogel was physically intermixed with PVA and the system crosslinked with borax [85]. An increase in borax content increases crosslinking density, which results in a compact structure with enhancement in mechanical properties. Glutaraldehyde was used as a crosslinker and hydrochloric acid as a catalyst for PVA-CNC and PVA-CNF xerogels. Upon adding nanocellulose, creep strain, and stress relaxation of the system reduced, and thermal 


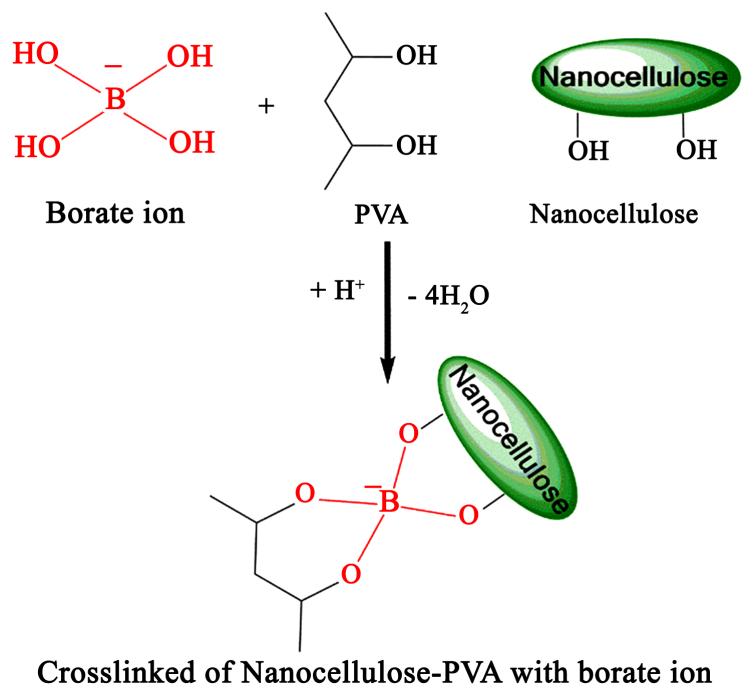

Figure 5. Crosslinking reaction of nanocellulose and polyvinyl alcohol (PVA) with borate ion.

deterioration was observed at a lower temperature. An investigation has been carried out on the reinforcement of CNCs prepared with formaldehyde as a crosslinking agent for PVA [86] [87]. With the introduction of CNCs to PVA, an increase in density and decrease in water uptake were observed because of the reduction in pore size.

\section{Silane as a Modifier for Cellulose}

The silanes considered here bear the general formula $\mathrm{R}-\mathrm{Si}-(\mathrm{X})_{3}$, where $\mathrm{X}$ is an oxy-alkyl group and $\mathrm{R}$ is an organic moiety, which is chosen as a function of the nature of the matrix. It seemed, therefore, appropriate to test them on cellulosic fibers, which bear the same potentially reactive groups, i.e., $\mathrm{OH}$ functions. The quantitative assessment of the physicochemical equilibrium for several silanes indicated that the adsorption of a monolayer and multiple layers of pre-hydrolyzed silanes is readily achieved but that a simple extraction with ethanol removes these molecules entirely. Only a heat treatment can induce a condensation between the $\mathrm{OH}$ groups of the hydrolyzed silanes and those present at the surface of cellulose, giving rise to a real chemical modification [88].

According to its structure, CNC possesses a considerable number of hydroxyl groups on the surface, where chemical reactions can be conducted [89]. The $\mathrm{OH}$ group at the sixth position acts as primary alcohol among the three kinds of hydroxyl groups, where the modification mostly occurs [90]. Many reactions can be used to modify the surface of nanocellulose, such as using coupling agents, that is, silane reagents [91]. The synergy of silane coupling agents with natural fibers is widely known [92], and the modification involves polymerization on the CNC surface [93]. Apart from this, silane coupling agents, such as aminopropyltrimethoxysilane, methyltrimethoxysilane, and vinyltrimethoxysilane, are widely employed to improve the compatibility between polymers and fibers, such as 
glass and natural fibers [94]. The authors subjected tunicin nanocrystals to partial silylation with a series of alkyldimethylchlorosilanes and found that the silanes are readily reactive with crystalline cellulose. However, the alkyldimethylsilylatednanocrystalslose their structural integrity and do not produce stable suspensions in very low polarity solvents. Recently, Mabrouk et al. prepared aqueous nanocomposite dispersions of poly (styrene-co2-ethyl hexylacrylate) copolymer and cellulose nanocrystals via mini-emulsion polymerization, using methacryloxypropyltrietoxysilane as a coupling agent [95] [96]. The authors showed that $1 \mathrm{wt} \%$ of silane is the optimum value for a reinforcement property, as higher values of silane, such as $3 \mathrm{wt} \%$, prevent the formation of percolated networks. Cellulose nanocrystals surface modification by using a silane with isocyanate groups (isocyanatepropyltriethoxysilane, IPTS), which are very reactive to hydroxyl groups, was followed by hydrolysis-condensation steps of ethoxy silane groups to produce an oligomeric network of polysilsesquioxane. Despite the small number of free hydroxyl groups, which is a characteristic of the highly crystalline nanocrystals surface, the formation of polysilsesquioxane can result in an efficient nanocrystal surface covering. As a result, urethane groups will be formed at the nanocrystal-siloxane interface, which can give stability against moisture.

The surface modification of nanocrystals with IPTS was carried out as an attempt to obtain nanocrystals with a reduced hydrophilic surface character, which could enhance the compatibility of these nanocrystals with hydrophobic matrices [97]. Figure 6 shows the reaction between IPTS and cellulose.

Epoxy resin (EP), with excellent comprehensive performance and a wide range of applications, has been the most researched thermosetting matrix of cellulose reinforced composites. The cellulose fibers were proved to have a good effect on improving the specific properties of the EP matrix. Fracture toughness and impact behavior were reported to have shown a significant increase after adding the cellulose fibers, while flexural strength and young's modulus hardly

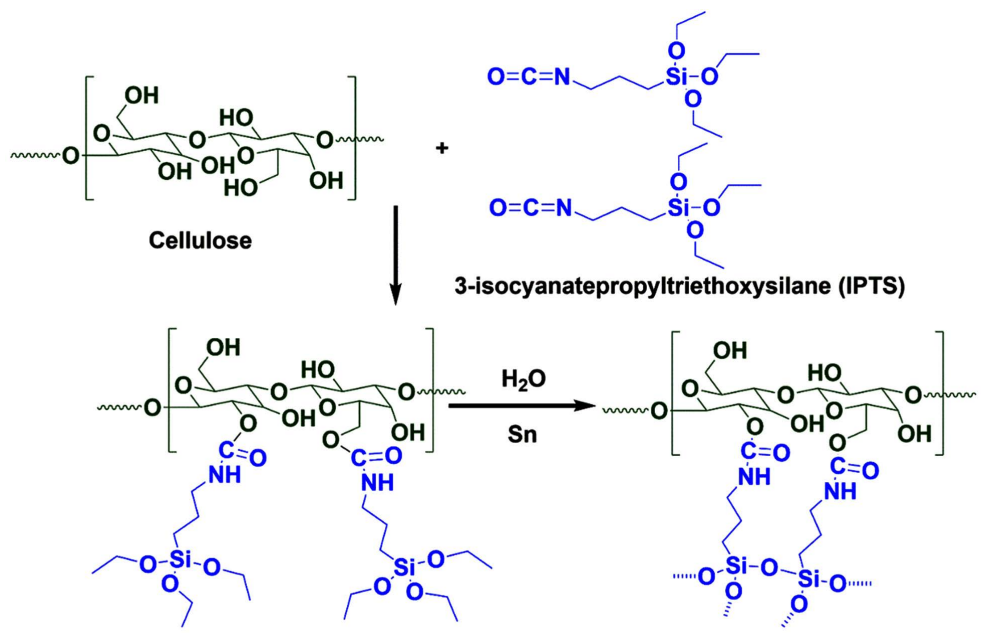

Figure 6. Chemical reaction between cellulose nanocrystal and IPTS. 
increased [98] [99] [100] [101]. The strength improvement was unsatisfied because of the poor compatibility between the cellulose and the matrix, which limited the application of the cellulose/EP composites. Thus, the poor compatibility between the cellulose fiber and the matrix is a problem we must overcome to get composites with high properties. The strong polarity of cellulose and highly dense hydrogen bonds between molecules and intra-molecules in its structure lead to reduced accessibility of matrix. Therefore, the interfacial tension between the cellulose fiber and the matrix is quite high, which leads to the peeling off the fibers and increase in the porosity in the composites [102] [103]. To improve the compatibility, physical, chemical, or other modifications of the cellulose are vital [104] [105].

3-Glycidoxypropyltrimethoxtsilane (GPTMS) with commercial name as KH560, a silane coupling agent, was used for modifying cellulose fibers obtained from bamboo [106]. The bamboo cellulose fibers were pretreated with silane coupling agent and $\mathrm{NaOH}$ aqueous solution (alkali treatment) and then incorporated in epoxy matrix. Compared to alkali treatment, bamboo cellulose fibers with silane treatment showed enhanced mechanical properties by reinforcement in the epoxy matrix. From various characterizations, the silane coupling agent made chemical bonds with the matrix and the filler in a composite. Figure 7 shows the reaction of bamboo cellulose with 3-(GPTMS). A study by Abdelmouleh et al. showed treatment of various silane on cellulose fibers and its incorporation in unsaturated polyester and epoxy resin matrices observed improvement in the interface of fiber and matrix with better reinforcement [107]. Flexural modulus showed better results when fiber incorporation up to $40 \%(\mathrm{v} / \mathrm{v})$ in the composite. 3-aminopropyl triethoxysilane (APS), methacrylopropyl trimethoxysilane (MPS), hexadecytrimethoxysilane, and mercaptopropyl trimethoxysilane (MRPS) were treated with cellulose fibers before incorporation in the matrix. The reaction of APS and MPS are shown in Figure 8. Although the interface was improved, these silane coupling agents could not prevent the water absorption in the composite.
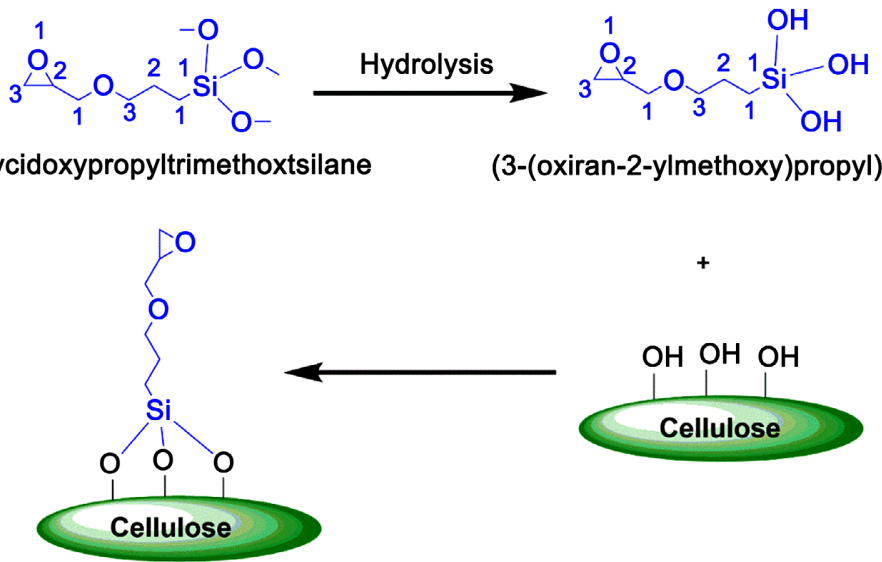

Figure 7. Surface modification of bamboo cellulose fibers using GPTMS. 


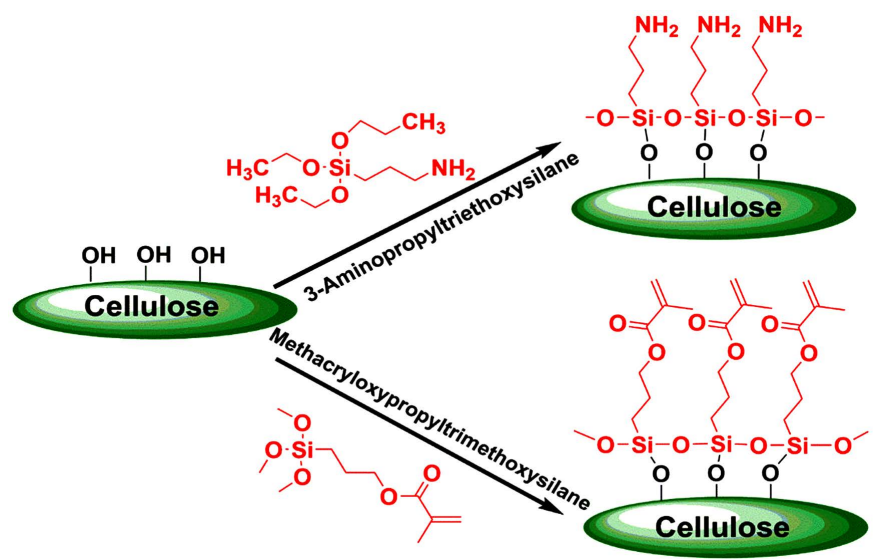

Figure 8. Reaction of cellulose fibers with silanes.

Silane coupling agent, (Bis[3-(triethoxysilyl)propyl]tetrasulfide), was utilized to modify the nanocellulose (NC) isolated from pineapple leaf fiber. Silane treatment reduced the particle size and enhanced the hydrophobicity NC [108]. It was observed from the research that the surface modification by vinyl trimethoxy silane induced functionalization which affected the physicochemical properties of the $E$. binata fibers and has a potential for making green polymer composites [109]. Silane reagents like primary, secondary, and tertiary amines of amino silanes have been used for cellulose modification [110]. The hydrolytically sensitive center can react with hydroxyl groups or silanols to form a silylated surface. APS and GPTMS modified MFC showed conversion of hydrophilic to hydrophobic nature and showed enhancement in mechanical property when the modified fibers were incorporated in an epoxy matrix [111].

\section{Conclusions}

The incorporation of cellulose in adhesives shows improvement in both mechanical properties of adhesives and performance properties. To further enhance the properties of adhesives, the establishment of chemical bonds in the system is a crucial step. According to cellulose structure, cellulose possesses $\mathrm{OH}$ group at the sixth position acts as primary alcohol among the three kinds of hydroxyl groups, where the modification mostly occurs. Crosslinking of cellulose is one such approach that significantly improves various properties. The advantage of the crosslinking of cellulose is to facilitate the interconnected network formation without any phase separation and to provide synergetic property of the adhesive and cellulose in the adhesive system. Aldehyde and borax crosslinked cellulose showed the formation of a crosslinked structure with the enhancement of mechanical and thermal properties.

To improve water resistance, mechanical, thermal properties and compatibility in resin matrix system, silane modification of cellulose is one such approach that significantly improves various properties. The cross-linking reaction had resulted in the formation of covalent bonds between the silanol bonds and hydroxy groups. Many reactions can be used to modify the surface of cellulose, such as us- 
ing coupling agents, that is, silane reagents like amino silane, epoxy silane, vinyl silane, isocyanate propyl triethoxy silane, Bis[3-(triethoxysilyl)propyl]tetrasulfide. Reinforcement of silane modified fibers resulted in significant changes of $\mathrm{Tg}$ and melting temperature $(\mathrm{Tm})$ with respect to virgin polymers like polylactic acid (PLA), epoxy resin with increased polymer crystallinity due to improved interfacial interactions. The improvement in the properties of the cellulose-based adhesive with the addition of the coupling agent was supported by its better compatibility and more covalent bond formation that resulted in enhanced thermal stability and increased bonding strength.

Hence by these principal investigations, the effective addition of silanemodified bio-based functional filler can be one of the ways for developing adhesive with better properties. With continuous research and development in bio-based adhesives, the possibilities of replacement for conventional petroleum-based material, thereby reducing the reliance on petrochemicals in the wood adhesive industry can be achieved.

\section{Conflicts of Interest}

The authors declare no conflicts of interest regarding the publication of this paper.

\section{References}

[1] Bhave, P.P. and Kulkarni, N. (2015) Air Pollution and Control Legislation in India. Journal of the Institution of Engineers (India): Series A, 96, 259-265. https://doi.org/10.1007/s40030-015-0125-Z

[2] Ragothaman, A. and Anderson, W.A. (2017) Air Quality Impacts of Petroleum Refining and Petrochemical Industries. Environments, 4, Article No. 66.

[3] Achudume, A.C. (2009) The Effect of Petrochemical Effluent on the Water Quality of Ubeji Creek in Niger Delta of Nigeria. Bulletin of Environmental Contamination and Toxicology, 83, 410-415. https://doi.org/10.3390/environments4030066

[4] Choi, C.J., Berges, J.A. and Young, E.B. (2012). Rapid Effects of Diverse Toxic Water Pollutants on Chlorophyll a Fluorescence: Variable Responses among Freshwater Microalgae. Water Research, 46, 2615-2626. https://doi.org/10.1016/j.watres.2012.02.027

[5] Wang, S., Xu, Y., Lin, Z., Zhang, J., Norbu, N. and Liu, W. (2017) The Harm of Petroleum-Polluted Soil and Its Remediation Research. AIP Conference Proceedings, 1864, Article ID: 020222. https://doi.org/10.1063/1.4993039

[6] UN Environment Programme (2018) Plastic Planet: How Tiny Plastic Particles Are Polluting Our Soil. UN Environment Programme: News \& Stories.

https://www.unep.org/news-and-stories/story/plastic-planet-how-tiny-plastic-partic les-are-polluting-our-soil

[7] Flaris, V. and Singh, G. (2009) Recent Developments in Biopolymers. Journal of Vinyl and Additive Technology, 15, 1-11. https://doi.org/10.1002/vnl.20171

[8] Tang, X.Z., Kumar, P., Alavi, S. and Sandeep, K.P. (2012) Recent Advances in Biopolymers and Biopolymer-Based Nanocomposites for Food Packaging Materials. Critical Reviews in Food Science and Nutrition, 52, 426-442.

https://doi.org/10.1080/10408398.2010.500508 
[9] Heinrich, L.A. (2019) Future Opportunities for Bio-Based Adhesives-Advantages beyond Renewability. Green Chemistry, 21, 1866-1888. https://doi.org/10.1039/C8GC03746A

[10] Haag, A.P., Maier, R.M., Combie, J. and Geesey, G.G. (2004) Bacterially Derived Biopolymers as Wood Adhesives. International Journal of Adhesion and Adhesives, 24, 495-502. https://doi.org/10.1016/j.ijadhadh.2004.01.004

[11] Kruger, L. and Lacourse, N. (1990) Starch Based Adhesives. In: Skeist, I., Ed., Handbook of Adhesives, Springer, Boston, 153-166. https://doi.org/10.1007/978-1-4613-0671-9_8

[12] Dhawale, P.V., Vineeth, S.K., Gadhave, R.V. and Mahanwar, P.A. (2021) Cellulose Stabilized Polyvinyl Acetate Emulsion: Review. Open Journal of Organic Polymer Materials, 11, 51-66. https://doi.org/10.4236/ojopm.2021.112002

[13] Luo, X. and Shuai, L. (2020) Lignin-Based Adhesives. In: Inamuddin, Boddula, R., Ahamed, M.I. and Asiri, A.M., Eds., Green Adhesives, John Wiley \& Sons, Hoboken, 25-56. https://doi.org/10.1002/9781119655053.ch2

[14] Zhou, X. and Du, G. (2020) Applications of Tannin Resin Adhesives in the Wood Industry. In: Aires, A., Ed., Tannins-Structural Properties, Biological Properties and Current Knowledge, IntechOpen, London, 1-19. https://doi.org/10.5772/intechopen.86424

[15] Gadhave, R.V., Vineeth, S.K., Dhawale, P.V. and Gadekar, P.T. (2020) Effect of Boric Acid on Poly Vinyl Alcohol-Tannin Blend and Its Application as Water-Based Wood Adhesive. Designed Monomers and Polymers, 23, 188-196. https://doi.org/10.1080/15685551.2020.1826124

[16] Shybi, A.A., Varghese, S. and Thomas, S. (2021) Natural Rubber Latex-Based Adhesives: Role of Nanofillers. Journal of Adhesion Science and Technology, 35, 406-418. https://doi.org/10.1080/01694243.2020.1806613

[17] Zeng, Y., et al. (2021) Soy Protein-Based Adhesive with Superior Bonding Strength and Water Resistance by Designing Densely Crosslinking Networks. European Polymer Journal, 142, Article ID: 110128. https://doi.org/10.1016/j.eurpolymj.2020.110128

[18] Vnučec, D., Kutnar, A. and Goršek, A. (2017) Soy-Based Adhesives for WoodBonding-A Review. Journal of Adhesion Science and Technology, 31, 910-931. https://doi.org/10.1080/01694243.2016.1237278

[19] Lei, H., Du, G., Wu, Z., Xi, X. and Dong, Z. (2014) Cross-Linked Soy-Based Wood Adhesives for Plywood. International Journal of Adhesion and Adhesives, 50, 199-203. https://doi.org/10.1016/j.ijadhadh.2014.01.026

[20] Mitachi, S., Hagiwara, A., Murata, N., Kojima, D., Falco, G. and Mija, A. (2015) Eco-Friendly Optical Adhesives Based onVegetable Oil Thermosets. Journal of The Adhesion Society of Japan, 51, 279-285, https://doi.org/10.11618/adhesion.51.279

[21] Sulaiman, N.S., Hashim, R., Sulaiman, O., Nasir, M., Amini, M.H.M. and Hiziroglu, S. (2018) Partial Replacement of Urea-Formaldehyde with Modified Oil Palm Starch Based Adhesive to Fabricate Particleboard. International Journal of Adhesion and Adhesives, 84, 1-8. https://doi.org/10.1016/j.ijadhadh.2018.02.002

[22] Jang, Y., Huang, J. and Li, K. (2011) A New Formaldehyde-Free Wood Adhesive from Renewable Materials. International Journal of Adhesion and Adhesives, 31, 754-759. https://doi.org/10.1016/j.ijadhadh.2011.07.003

[23] Prasittisopin, L. and Li, K. (2010) A New Method of Making Particleboard with a Formaldehyde-Free Soy-Based Adhesive. Composites Part A: Applied Science and Manufacturing, 41, 1447-1453. https://doi.org/10.1016/j.compositesa.2010.06.006 
[24] Pizzi, A. (2006) Recent Developments in Eco-Efficient Bio-Based Adhesives for Wood Bonding: Opportunities and Issues. Journal of Adhesion Science and Technology, 20, 829-846. https://doi.org/10.1163/156856106777638635

[25] Heinrich, L.A. (2019) Future Opportunities for Bio-Based Adhesives-Advantages beyond Renewability. Green Chemistry, 21, 1866-1888.

https://doi.org/10.1039/C8GC03746A

[26] Klemm, D., Heublein, B., Fink, H.P. and Bohn, A. (2005) Cellulose: Fascinating Biopolymer and Sustainable Raw Material. Angewandte Chemie International Edition, 44, 3358-3393. https://doi.org/10.1002/anie.200460587

[27] Stenstad, P., Andresen, M., Tanem, B.S. and Stenius, P. (2008) Chemical Surface Modifications of Microfibrillated Cellulose. Cellulose, 15, 35-45. https://doi.org/10.1007/s10570-007-9143-y

[28] Kalia, S., et al. (2011) Cellulose-Based Bio- and Nanocomposites: A Review. International Journal of Polymer Science, 2011, Article ID: 837875. https://doi.org/10.1155/2011/837875

[29] Moon, R.J., Martini, A., Nairn, J., Simonsen, J. and Youngblood, J. (2011) Cellulose Nanomaterials Review: Structure, Properties and Nanocomposites. Chemical Society Reviews, 40, 3941-3994. https://doi.org/10.1039/c0cs00108b

[30] Singh, H.K., Patil, T., Vineeth, S.K., Das, S., Pramanik, A. and Mhaske, S.T. (2019). Isolation of Microcrystalline Cellulose from Corn Stover with Emphasis on Its Constituents: Corn Cover and Corn Cob. Materials Today: Proceedings, 27, 589-594. https://doi.org/10.1016/j.matpr.2019.12.065

[31] Masoodia, R., El-Hajjar, R.F., Pillai, K.M. and Sabo, R. (2012) Mechanical Characterization of Cellulose Nanofiber and Bio-Based Epoxy Composite. Materials \& Design, 36, 570-576. https://doi.org/10.1016/j.matdes.2011.11.042

[32] Jang, J.Y., Jeong, T.K., et al. (2012) Thermal Stability and Flammability of Coconut Fiber Reinforced Poly(Lactic Acid) Composites. Composites Part B: Engineering, 43, 2434-2438. https://doi.org/10.1016/j.compositesb.2011.11.003

[33] Canche-Escamilla, G., Rodriguez-Laviada, J., Cauich-Cupul, J.I., Mendizabal, E., et al. (2002) Flexural, Impact and Compressive Properties of a Rigid-Thermoplastic Matrix/Cellulose Fiber Reinforced Composites. Composites Part A: Applied Science and Manufacturing, 33, 539-549.

https://doi.org/10.1016/S1359-835X(01)00136-1

[34] Sdrobis, A., Darie, R.N., et al. (2012) Low Density Polyethylene Composites Containing Cellulose Pulp Fibers. Composites Part B: Engineering, 43, 1873-1880. https://doi.org/10.1016/j.compositesb.2012.01.064

[35] Kowalczyk, M., Piorkowska, E., Kulpinski, P. and Pracella, M. (2011) Mechanical and Thermal Properties of PLA Composites with Cellulose Nanofibers and Standard Size Fibers. Composites Part A: Applied Science and Manufacturing, 42, 1509-1514. https://doi.org/10.1016/j.compositesa.2011.07.003

[36] Shi, Q.F., Zhou, C.G., Yue, Y.Y., et al. (2012) Mechanical Properties and in Vitro Degradation of Electrospun Bio-Nanocomposite Mats from PLA and Cellulose Nanocrystals. Carbohydrate Polymers, 90, 301-308. https://doi.org/10.1016/j.carbpol.2012.05.042

[37] Avella, M., Martuscelli, E. and Pascucci, B. (2012) Flexural Properties Loss of Unidirectional Epoxy/Fique Composites Immersed in Water and Alkaline Medium for Construction Application. Composites Part B: Engineering, 43, 3120-3130. https://doi.org/10.1016/j.compositesb.2012.04.027 
[38] Houde, A.Y. and Stern, S.A. (1997) Solubility and Diffusivity of Light Gases in Ethyl Cellulose at Elevated Pressures Effects of Ethoxy Content. Journal of Membrane Science, 127, 171-183. https://doi.org/10.1016/S0376-7388(96)00266-9

[39] Kabir, M.M., Wang, H., et al. (2012) Mechanical Properties of Chemically-Treated Hemp Fibre Reinforced Sandwich Composites. Composites Part B: Engineering, 43, 159-169. https://doi.org/10.1016/j.compositesb.2011.06.003

[40] Lin, X., Chen, S.Y., Hu, W.L., et al. (2009) In Situ Synthesis of CdS Nanoparticles on Bacterial Cellulose Nanofibers. Carbohydrate Polymers, 76, 509-512. https://doi.org/10.1016/j.carbpol.2008.11.014

[41] Pandey, J.K., Takagi, H., et al. (2012) An Overview on the Cellulose Based Conducting Composites. Composites Part B: Engineering, 43, 2822-2866. https://doi.org/10.1016/j.compositesb.2012.04.045

[42] He, J., Kunitake, T. and Nakao, A. (2003) Facile in Situ Synthesis of Noble Metal Nanoparticles in Porous Cellulose Fibers. Chemistry of Materials, 15, 4401-4406. https://doi.org/10.1021/cm034720r

[43] Khulbe, K.C., Matsuura, T. and Feng, C.Y. (2002) Study on Cellulose Acetate Membranes for Reverse Osmosis and Polyethersulfone Membranes for Ultrafiltration by Electron Spin Resonance Technique. Desalination, 148, 329-332. https://doi.org/10.1016/S0011-9164(02)00725-7

[44] Lu, T., Jiang, M., Jiang, Z., Hui, D., Wang, Z. and Zhou, Z. (2013) Effect of Surface Modification of Bamboo Cellulose Fibers on Mechanical Properties of Cellulose/Epoxy Composites. Composites Part B: Engineering, 51, 28-34. https://doi.org/10.1016/j.compositesb.2013.02.031

[45] Vineeth, S.K., Gadhave, R.V and Gadekar, P.T. (2019) Nanocellulose Applications in Wood Adhesives-Review. Open Journal of Polymer Chemistry, 9, 63-75. https://doi.org/10.4236/ojpchem.2019.94006

[46] Veigel, S., Rathke, J., Weigl, M. and Gindl-Altmutter, W. (2012) Particle Board and Oriented Strand Board Prepared with Nanocellulose-Reinforced Adhesive. Journal of Nanomaterials, 2012, Article ID: 158503. https://doi.org/10.1155/2012/158503

[47] Mahrdt, E., Pinkl, S., Schmidberger, C., van Herwijnen, H.W.G., Veigel, S. and Gindl-Altmutter, W. (2016) Effect of Addition of Microfibrillated Cellulose to UreaFormaldehyde on Selected Adhesive Characteristics and Distribution in Particle Board. Cellulose, 23, 571-580. https://doi.org/10.1007/s10570-015-0818-5

[48] Tayeb, A.H., Amini, E., Ghasemi, S. and Tajvidi, M. (2018) Cellulose Nanomaterials-Binding Properties and Applications: A Review. Molecules, 23, Article ID: 2684.

[49] Grüneberger, F., Künniger, T., Zimmermann, T. and Arnold, M. (2014) Nanofibrillated Cellulose in Wood Coatings: Mechanical Properties of Free Composite Films. Journal of Materials Science, 49, 6437-6448. https://doi.org/10.1007/s10853-014-8373-2

[50] Dastjerdi, Z., Cranston, E.D. and Dubé, M.A. (2018) Pressure Sensitive Adhesive Property Modification Using Cellulose Nanocrystals. International Journal of Adhesion and Adhesives, 81, 36-42. https://doi.org/10.1016/j.ijadhadh.2017.11.009

[51] Veigel, S., Müller, U., Keckes, J., Obersriebnig, M. and Gindl-Altmutter, W. (2011) Cellulose Nanofibrils as Filler for Adhesives: Effect on Specific Fracture Energy of Solid Wood-Adhesive Bonds. Cellulose, 18, 1227-1237. https://doi.org/10.1007/s10570-011-9576-1

[52] Gindl-Altmutter, W. and Veigel, S. (2014) Nanocellulose-Modified Wood Adhesives. In: Oksman, K., Mathew, A.P., Bismarck, A., Rojas, O. and Sain, M., Eds., 
Handbook of Green Materials, World Scientific Publishing, Singapore, 253-264. https://doi.org/10.1142/9789814566469_0031

[53] Cataldi, A., Berglund, L., Deflorian, F. and Pegoretti, A. (2015) A Comparison between Micro- and Nanocellulose-Filled Composite Adhesives for Oil Paintings Restoration. Nanocomposites, 1, 195-203. https://doi.org/10.1080/20550324.2015.1117239

[54] Tajvidi, M., Gardner, D.J. and Bousfield, D.W. (2016) Cellulose Nanomaterials as Binders: Laminate and Particulate Systems. Journal of Renewable Materials, 4, 365-376. https://doi.org/10.7569/JRM.2016.634103

[55] Jiang, W., Haapala, A., Tomppo, L., Pakarinen, T., Sirviö, J.A. and Liimatainen, H. (2018) Effect of Cellulose Nanofibrils on the Bond Strength of Polyvinyl Acetate and Starch Adhesives for Wood. BioResources, 13, 2283-2292. https://doi.org/10.15376/biores.13.2.2283-2292

[56] López-Suevos, F., Eyholzer, C., Bordeanu, N. and Richter, K. (2010) DMA Analysis and Wood Bonding of PVAc Latex Reinforced with Cellulose Nanofibrils. Cellulose, 17, 387-398. https://doi.org/10.1007/s10570-010-9396-8

[57] Kaboorani, A., Riedl, B., Blanchet, P., Fellin, M., Hosseinaei, O. and Wang, S. (2012) Nanocrystalline Cellulose (NCC): A Renewable Nano-Material for Polyvinyl Acetate (PVA) Adhesive. European Polymer Journal, 48, 1829-1837. https://doi.org/10.1016/j.eurpolymj.2012.08.008

[58] Cui, J., et al. (2015) Enhancement of Mechanical Strength of Particleboard Using Environmentally Friendly Pine (Pinus pinaster L.) Tannin Adhesives with Cellulose Nanofibers. Annals of Forest Science, 72, 27-32. https://doi.org/10.1007/s13595-014-0392-2

[59] Zhang, H., Zhang, J., Song, S., Wu, G. and Pu, J. (2011) Modified Nanocrystalline Cellulose from Two Kinds Emission and Bonding Strength of Urea-Fromaldehyde Resin Adhesive. BioResources, 6, 4430-4438.

[60] Gao, Q., Li, J., Shi, S.Q., Liang, K. and Zhang, X. (2012) Soybean Meal-Based Adhesive Reinforced with Cellulose Nano-Whiskers. BioResources, 7, 5622-5633. https://doi.org/10.15376/biores.7.4.5622-5633

[61] Kojima, Y., et al. (2013) Binding Effect of Cellulose Nanofibers in Wood Flour Board. Journal of Wood Science, 59, 396-401. https://doi.org/10.1007/s10086-013-1348-0

[62] Kojima, Y., et al. (2014) Evaluation of Binding Effects in Wood Flour Board Containing Ligno-Cellulose Nanofibers. Materials (Base), 7, 6853-6864.

[63] Ayrilmis, N., Lee, Y.K., Kwon, J.H., Han, T.H. and Kim, H.J. (2016) Formaldehyde Emission and VOCs from LVLs Produced with Three Grades of Urea-Formaldehyde Resin Modified with Nanocellulose. Building and Environment, 97, 82-87. https://doi.org/10.1016/j.buildenv.2015.12.009

[64] Via, B.K., Fasina, O. and Atta-Obeng, E. (2012) Effect of Microcrystalline Cellulose, Species, and Particle Size on Mechanical and Physical Properties of Particleboard. Wood and Fiber Science, 44, 227-235.

[65] Hunt, J.F., Leng, W. and Tajvidi, M. (2017) Vertical Density Profile and Internal Bond Strength of Wet-Formed Particleboard Bonded with Cellulose Nanofibrils. Wood and Fiber Science, 49, 413-423.

[66] Diop, C.I.K., Tajvidi, M., Bilodeau, M.A., Bousfield, D.W. and Hunt, J.F. (2017) Evaluation of the Incorporation of Lignocellulose Nanofibrils as Sustainable Adhesive Replacement in Medium Density Fiberboards. Industrial Crops and Products, 109, 27-36. https://doi.org/10.1016/j.indcrop.2017.08.004 
[67] Amini, E., Tajvidi, M., Gardner, D.J. and Bousfield, D.W. (2017) Utilization of Cellulose Nanofibrils as a Binder for Particleboard Manufacture. BioResources, 12, 4093-4110. https://doi.org/10.15376/biores.12.2.4093-4110

[68] Cheng, H.N., Kilgore, K., Ford, C., Fortier, C., Dowd, M.K. and He, Z. (2019) Cottonseed Protein-Based Wood Adhesive Reinforced with Nanocellulose. Journal of Adhesion Science and Technology, 33, 1357-1368. https://doi.org/10.1080/01694243.2019.1596650

[69] Oh, M., Ma, Q., Simsek, S., Bajwa, D. and Jiang, L. (2019) Comparative Study of Zein- and Gluten-Based Wood Adhesives Containing Cellulose Nano Fibers and Crosslinking Agent for Improved Bond Strength. International Journal of Adhesion and Adhesives, 92, 44-57. https://doi.org/10.1016/j.ijadhadh.2019.04.004

[70] Zhang, H., Liu, P., Musa, S., Mai, C. and Zhang, K. (2019) Dialdehyde Cellulose as a Bio-Based Robust Adhesive for Wood Bonding. ACS Sustainable Chemistry \& Engineering, 7, 10452-10459. https://doi.org/10.1021/acssuschemeng.9b00801

[71] Kwon, J.H., Lee, S.H., Ayrilmis, N. and Han, T.H. (2015) Tensile Shear Strength of Wood Bonded with Urea-Formaldehyde with Different Amounts of Microfibrillated Cellulose. International Journal of Adhesion and Adhesives, 60, 88-91.

[72] Chen, H., Nair, S.S., Chauhan, P. and Yan, N. (2019) Lignin Containing Cellulose Nanofibril Application in pMDI Wood Adhesives for Drastically Improved Gap-Filling Properties with Robust Bondline Interfaces. Chemical Engineering Journal, 360, 393-401. https://doi.org/10.1016/j.cej.2018.11.222

[73] Salon, M.C.B., Bayle, P.A., Abdelmouleh, M., Boufi, S. and Belgacem, M.N. (2008) Kinetics of Hydrolysis and Self-Condensation Reaction of Silanes by NMR Spectroscopy. Colloids and Surfaces A: Physicochemical and Engineering Aspects, 312, 83-91. https://doi.org/10.1016/j.colsurfa.2007.06.028

[74] Donath, S., Militz, H. and Mai, C. (2006) Creating Water-Repellent Effects on Wood Bytreatment with Silanes. Holzforschung, 60, 40-46.

[75] Abdelmouleh, M., Boufi, S., ben Salah, A., Belgacem, M.N. and Gandini, A. (2002) Interaction Ofsilane Coupling Agents with Cellulose. Langmuir, 18, 3203-3208. https://doi.org/10.1021/la011657g

[76] Averous, L. (2009) Biodegradable Polymer Blends and Composites from Renewable Resources. Macromolecular Chemistry and Physics, 210, 890. https://doi.org/10.1002/macp.200900141

[77] Bledzki, A.K., Reihmane, S. and Gassan, J. (1996) Properties and Modification Methods for Vegetable Fibers for Natural Fiber Composites. Journal of Applied Polymer Science, 59, 1329-1336. https://doi.org/10.1002/(SICI)1097-4628(19960222)59:8<1329::AID-APP17>3.0.CO $\underline{; 2-0}$

[78] Hornsby, P.R., Hinrichsen, E. and Tarverdi, K. (1997) Preparation and Properties of Polypropylene Composites Reinforced with Wheat and Flax Straw Fibres: Part II Analysis of Composite Microstructure and Mechanical Properties. Journal of Materials Science, 32, 1009-1015. https://doi.org/10.1023/A:1018578322498

[79] Oksman, K., Wallstrom, L., Berglund, L.A. and Filho, R.D.T. (2002) Morphology and Mechanical Properties of Unidirectional Sisal-Epoxy Composites. Journal of Applied Polymer Science, 84, 2358-2365. https://doi.org/10.1002/app.10475

[80] Saheb, D.N. and Jog, J.P. (1999) Natural Fiber Polymer Composites: A Review. Advances in Polymer Technology, 18, 351-363.

https://doi.org/10.1002/(SICI)1098-2329(199924)18:4<351::AID-ADV6>3.0.CO;2-X 
[81] Georgopoulos, S.T., Tarantili, P.A., Avgerinos, E., Andreopoulos, A.G. and Koukios, E.G. (2005) Thermoplastic Polymers Reinforced with Fibrous Agricultural Residues. Polymer Degradation and Stability, 90, 303-312. https://doi.org/10.1016/j.polymdegradstab.2005.02.020

[82] Tanpichai, S. and Oksman, K. (2016) Cross-Linked Nanocomposite Hydrogels Based on Cellulose Nanocrystals and PVA: Mechanical Properties and Creep Recovery. Composites Part A: Applied Science and Manufacturing, 88, 226-233. https://doi.org/10.1016/j.compositesa.2016.06.002

[83] Tanpichai, S. and Oksman, K. (2018) Crosslinked Poly(Vinyl Alcohol) Composite Films with Cellulose Nanocrystals: Mechanical and Thermal Properties. Journal of Applied Polymer Science, 135, Article ID: 45710. https://doi.org/10.1002/app.45710

[84] Sirviö, J.A., Honkaniemi, S., Visanko, M. and Liimatainen, H. (2015) Composite Films of Poly(Vinyl Alcohol) and Bifunctional Cross-Linking Cellulose Nanocrystals. ACS Applied Materials \& Interfaces, 7, 19691-19699. https://doi.org/10.1021/acsami.5b04879

[85] Spoljaric, S., Salminen, A., Luong, N.D. and Seppälä, J. (2014) Stable, Self-Healing Hydrogels from Nanofibrillated Cellulose, Poly(Vinyl Alcohol) and Borax via Reversible Crosslinking. European Polymer Journal, 56, 105-117. https://doi.org/10.1016/j.eurpolymj.2014.03.009

[86] Pramanik, R., Ganivada, B., Ram, F., Shanmuganathan, K. and Arockiarajan, A. (2019) Influence of Nanocellulose on Mechanics and Morphology of Polyvinyl Alcohol Xerogels. The Journal of the Mechanical Behavior of Biomedical Materials, 90, 275-283. https://doi.org/10.1016/j.jmbbm.2018.10.024

[87] Song, T., Tanpichai, S. and Oksman, K. (2016) Cross-Linked Polyvinyl Alcohol (PVA) Foams Reinforced with Cellulose Nanocrystals (CNCs). Cellulose, 23, 1925-1938. https://doi.org/10.1007/s10570-016-0925-y

[88] Abdelmouleh, M., Boufi, S., ben Salah, A., Belgacem, M.N. and Gandini, A. (2002) Interaction of Silane Coupling Agents with Cellulose. Langmuir, 18, 3203-3208. https://doi.org/10.1021/la011657g

[89] Salas, C., Nypelö, T., Rodriguez-Abreu, C., Carrillo, C. and Rojas, O.J. (2014) Nanocellulose Properties and Applications in Colloids and Interfaces. Current Opinion in Colloid \& Interface Science, 19, 383-396. https://doi.org/10.1016/j.cocis.2014.10.003

[90] Hajlane, A. (2014) Development of Hierarchical Cellulosic Reinforcement for Polymer Composites. Licentiate Thesis, Luleå Tekniska Universitet, Luleå.

[91] Eyley, S. and Thielemans, W. (2014) Surface Modification of Cellulose Nanocrystals. Nanoscale, 6, 7764-7779. https://doi.org/10.1039/C4NR01756K

[92] Kalia, S., Boufi, S., Celli, A. and Kango, S. (2014) Nanofibrillated Cellulose: Surface Modification and Potential Applications. Colloid and Polymer Science, 292, 5-31. https://doi.org/10.1007/s00396-013-3112-9

[93] Mohd, N.H., Ismail, N.F.H., Zahari, J.I., Wan Fathilah, W.F., Kargarzadeh, H., Ramli, S. and Othaman, R. (2016) Effect of Aminosilane Modification on Nanocrystalline Cellulose Properties. Journal of Nanomaterials, 2016, Article ID: 4804271. https://doi.org/10.1155/2016/4804271

[94] Xie, K., Yu, Y. and Shi, Y. (2009) Synthesis and Characterization of Cellulose/Silica Hybrid Materials with Chemical Crosslinking. Carbohydrate Polymers, 78, 799-805. https://doi.org/10.1016/j.carbpol.2009.06.019

[95] Mabrouk, A.B., Kaddami, H., Magnin, A., Belgacem, M.N., Dufresne, A. and Boufi, S. (2011) Preparation of Nanocomposite Dispersions Based on Cellulose Whiskers 
and Acrylic Copolymer by Miniemulsion Polymerization: Effect of the Silane Content. Polymer Engineering \& Science, 51, 62-70. https://doi.org/10.1002/pen.21778

[96] Xie, Y., Hill, C.A.S., Xiao, Z., Militz, H. and Mai, C. (2010) Silane Coupling Agents Used for Natural Fiber/Polymer Composites: A Review. Composites Part A: Applied Science and Manufacturing, 41, 806-819.

https://doi.org/10.1016/j.compositesa.2010.03.005

[97] De Oliveira Taipina, M., Ferrarezi, M.M.F., Yoshida, I.V.P. and Gonçalves, M. (2013) Surface Modification of Cotton Nanocrystals with a Silane Agent. Cellulose, 20, 217-226. https://doi.org/10.1007/s10570-012-9820-3

[98] Low, I.M., McGrath, M., et al. (2007) Mechanical and Fracture Properties of Cellulose Fibre-Reinforced Epoxy Laminates. Composites Part A: Applied Science and Manufacturing, 38, 963-974. https://doi.org/10.1016/j.compositesa.2006.06.019

[99] Hsieh, K.H., Han, J.L., et al. (2001) Graft Interpenetrating Polymer Networks of Urethane Modified Bismaleimide and Epoxy (I): Mechanical Behavior and Morphology. Polymer, 42, 2912-2917. https://doi.org/10.1016/S0032-3861(00)00641-8

[100] Alamri, H. and Low, I.M. (2012) Mechanical Properties and Water Absorption Behaviour of Recycled Cellulose Fibre Reinforced Epoxy Composites. Polymer Testing, 31, 620-628. https://doi.org/10.1016/j.polymertesting.2012.04.002

[101] Shih, Y.F. (2007) Mechanical and Thermal Properties of Waste Water Bamboo Husk Fiber Reinforced Epoxy Composites. Materials Science and Engineering: $A$, 445-446, 289-295. https://doi.org/10.1016/j.msea.2006.09.032

[102] Mohamed, H.G., Mostafa, A.E., Kazuya, O. and Toru, F. (2010) Effect of Microfibrillated Cellulose on Mechanical Properties of Plain-Woven CFRP Reinforced Epoxy. Composite Structures, 92, 1999-2006.

https://doi.org/10.1016/j.compstruct.2009.12.009

[103] Reddy, K.O., Maheswari, C.U., et al. (2013) Tensile and Structural Characterization of Alkali Treated Borassus Fruit Fine Fibers. Composites Part B: Engineering, 44, 433-438. https://doi.org/10.1016/j.compositesb.2012.04.075

[104] Mishra, S., Misra, M., Tripathy, S.S., et al. (2002) The Influence of Chemical Surface Modification on the Performance of Sisal-Polyester Biocomposites. Polymer Composites, 23, 164-170. https://doi.org/10.1002/pc.10422

[105] Jarukumjorn, K. and Suppakarn, N. (2009) Effect of Glass Fiber Hybridization on Properties of Sisal Fiber-Polypropylene Composites. Composites Part B: Engineering, 40, 623-627. https://doi.org/10.1016/j.compositesb.2009.04.007

[106] Lu, T., Jiang, M., Jiang, Z., Hui, D., Wang, Z. and Zhou, Z. (2013) Effect of Surface Modification of Bamboo Cellulose Fibers on Mechanical Properties of Cellulose/Epoxy Composites. Composites Part B: Engineering, 51, 28-34. https://doi.org/10.1016/j.compositesb.2013.02.031

[107] Abdelmouleh, M., Boufi, S., Belgacem, M.N., Dufresne, A. and Gandini, A. (2005) Modification of Cellulose Fibers with Functionalized Silanes: Effect of the Fiber Treatment on the Mechanical Performances of Cellulose-Thermoset Composites. Journal of Applied Polymer Science, 98, 974-984. https://doi.org/10.1002/app.22133

[108] Gao, T.M., Huang, M.F., Li, P.W., Han, Z.P., Xie, R.H. and Chen, H.L. (2012) Preparation and Characterization Nano-Cellulose and its Surface Modification by Silane Coupling Agent. Applied Mechanics and Materials, 217-219, 260-263. https://doi.org/10.4028/www.scientific.net/AMM.217-219.260

[109] Thakur, M.K., Gupta, R.K. and Thakur, V.K. (2014) Surface Modification of Cellulose Using Silane Coupling Agent. Carbohydrate Polymers, 111, 849-855. 
https://doi.org/10.1016/j.carbpol.2014.05.041

[110] Sanaeepur, H., Kargari, A. and Nasernejad, B. (2014) Aminosilane Functionalization of a Nanoporous Y-Type Zeolite for Application in a Cellulose Acetate Based Mixed Matrix Membrane for CO2 Separation. RSC Advances, 4, 63966-63976, https://doi.org/10.1039/C4RA08783F

[111] Lu, J., Askeland, P. and Drzal, L.T. (2008) Surface Modification of Microfibrillated Cellulose for Epoxy Composite Applications. Polymer, 49, 1285-1296.

https://doi.org/10.1016/j.polymer.2008.01.028 